\section{MOBILE AND MANOEUVRABLE CHAIR INTRODUCED}

General Medical are UK distributors for Brumaba OP, including the Primus Operating Table. Stable, mobile and manoeuvrable the Brumaba OP Primus is the perfect solution for implantologists and other surgical specialists.

Its manoeuvrability means the surgeon can place the patient in exactly the right position within the surgical environment at exactly the right time. It features a patented dual-telescopic headrest which allows the patient's head to be perfectly positioned for optimum access; lateral side-tilting, so that patients can be positioned three dimensionally for further enhanced access and a more efficient way of working; and a patented dual-telescopic column so that the height can be adjusted from $520 \mathrm{~mm}$ to $960 \mathrm{~mm}$ to suit individual operator preferences, leaving generous legroom for those who prefer to operate seated.

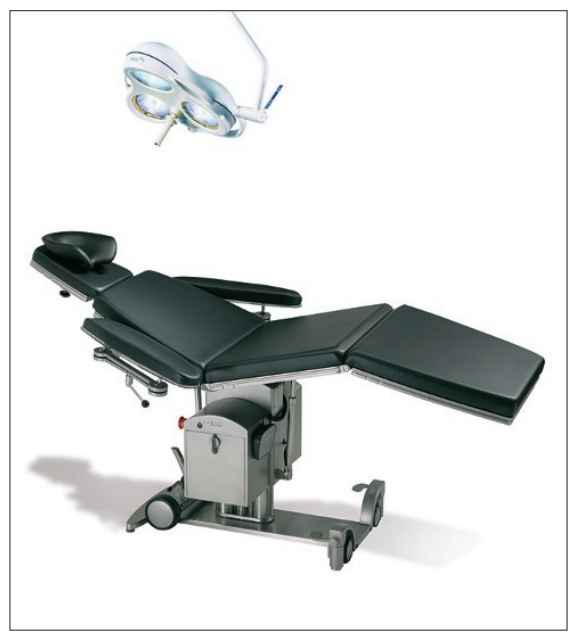

Simple to use and handle, the tried and tested Brumaba system supports the clinician and their team from the moment the patient is received in the operating area up until post-operational recovery - without ever needing to transfer the patient from one table to another. It is simple to clean and disinfect afterwards.

Reader response number 58

\title{
WEBINAR LECTURES LAUNCHED FOR 2010
}

UK dental training company Tipton Training Ltd is to launch a cyber e-learning programme for dentists which will allow them to top up their CPD and receive continued support from the training team at Tipton Training.

The series of high-tech webinars will allow dentists all over the UK to hear of the latest new dental techniques through a series of innovative online conferences.

The academy will sit alongside a new and enhanced course programme for 2010 and its members will also benefit from discounts and concessions against further, class-room based training as well as cutting-edge dentistry news.

It will be open to all current and past delegates of Tipton Training as well as any other dentists wishing to continue their professional development for a small fee.

The new course schedule set for 2010 will focus on specialist restorative, implant and phantom head courses as well as programmes for all dental care professionals including therapists, hygienists and dental nurses. Reader response number 59

\section{ONE DAY COURSE}

DentEd's one day course in Leeds, 'Radiography and Radiation Protection/Law \& Ethics', will provide 6.5 hours of core CPD for dentists and five hours for DCPs.

It works in association with Dentaid, the global oral health charity and is committed to supporting the effort to raise awareness of dental care in places around the world where there is currently significant under provision.

Going forward, DentEd plans to support the Bright Bites initiative, a project run by Dentaid to raise awareness of oral health amongst school children in the UK. Its next full day course is being held at Bodington Hall, University of Leeds on 22 April.

Reader response number 60 